\title{
COVID-19 Vaccination and Intention to Vaccinate Among a Sample of College Students in New Jersey
}

\author{
Aleksandar Kecojevic $^{1}$ (C) Corey H. Basch ${ }^{1} \cdot$ Marianne Sullivan ${ }^{1} \cdot$ Yen-Tyng Chen ${ }^{1} \cdot$ Nicole K. Davi $^{2}$
}

Accepted: 20 April 2021 / Published online: 27 April 2021

(c) The Author(s), under exclusive licence to Springer Science+Business Media, LLC, part of Springer Nature 2021

\begin{abstract}
Vaccines are critical for curtailing the COVID-19 pandemic and may represent an important tool for return to "normalcy" on college campuses in the Fall of 2021. The purpose of this study was to investigate the extent of vaccination coverage and intention to vaccinate among college students. College students $(\mathrm{N}=457)$ enrolled in the Spring 2021 semester at a university in New Jersey completed a cross-sectional survey. The survey collected information on demographics, COVID-19 and vaccination history, knowledge levels and sources of COVID-19 vaccine information, and vaccine attitudes. Multivariable regression analysis was performed to identify factors associated with vaccination, and the intention to vaccinate among non-vaccinated students. Results indicate that $23 \%(\mathrm{n}=105)$ of participants reported being vaccinated already. Among nonvaccinated students, $52.8 \%$ indicated their intention to receive the vaccine when it is made available to college students. Students who were health care workers (adjusted odds ratio, $\mathrm{aOR}=4.17, \mathrm{p}<0.001$ ), had a family member who had received a COVID-19 vaccine $(\mathrm{aOR}=5.03, \mathrm{p}<0.001)$, exhibited greater positive attitudes regarding vaccination $(\mathrm{aOR}=1.12, \mathrm{p}<0.001)$, and received a seasonal flu vaccine $(\mathrm{aOR}=1.97, \mathrm{p}<0.05)$ were more likely to have received the COVID-19 vaccine. Among non-vaccinated students, those who discussed COVID-19 vaccine information with others $(\mathrm{aOR}=5.38, \mathrm{p}<0.001)$, and exhibited more overall positive attitudes regarding vaccination $(\mathrm{aOR}=2.69, \mathrm{p}<0.001)$, were more likely to indicate their willingness to receive the COVID-19 vaccine. Findings of this study highlight the need for additional education and vaccine outreach aimed at promoting uptake of the COVID-19 vaccine among college students.
\end{abstract}

Keywords COVID-19 College students $\cdot$ Vaccine $\cdot$ Attitude $\cdot$ Intention

\section{Introduction}

The COVID-19 pandemic has significantly impacted the lives and education of college students $[1,2]$. With an increased supply of COVID-19 vaccines, students across the country are becoming eligible for vaccination $[3,4]$, thus giving a hope that college campuses could return to some form of normalcy by the fall. The vaccine-based protection can be maximized if there is a sufficient number of college students vaccinated, thus allowing college campus return to in-person classes, large group activities, return of college sports, study abroad opportunities, and social gatherings.

Aleksandar Kecojevic

kecojevica@wpunj.edu

1 Department of Public Health, College of Science and Health, William Paterson University, Wayne, USA

2 Department of Environmental Science, College of Science and Health, William Paterson University, Wayne, USA
The American College Health Association (ACHA) recommends that colleges and universities reach out to the appropriate public health authority to be included in the planning and distribution of the vaccine for students and other campus community members even before the end of the Spring term to prevent students from spreading the virus as they disperse over the summer [5]. Furthermore, some universities have already announced that they will mandate students attending classes in person to be vaccinated [6].

In order for vaccines to benefit the population at large, they need to be widely accepted by the public [7]. While the share of Americans who are planning to get vaccinated has increased [8], differences across demographic groups remain. For example, it appears that the intent to get vaccinated for COVID-19 is lower among younger adults [8]. This is of no surprise, as vaccine hesitancy was a significant issue even before COVID-19 [9], and in particular among young people [10]. Younger individuals may believe that COVID19 poses a less serious threat to themselves than to other 
age groups [11]. Furthermore, vaccine hesitancy remains higher in some minority communities, which is rooted in prior injustices that have resulted in mistrust of the medical system [12, 13].

More recently, several studies emerged examining college students' attitudes toward and intent to receive the COVID-19 vaccine. Two studies from Italy show that a high percentage of college students expressed intent to vaccinate $[14,15]$. In the U.S., several studies explored hesitancy and intentions among health professions students. A study of nursing faculty and students indicated that only $45 \%$ of students intended to get vaccinated [16]. Another study of medical students found $23 \%$ were unwilling to receive the COVID-19 vaccine immediately upon Food and Drugs Administration (FDA) approval [17]. A few studies have also investigated COVID vaccination intentions and attitudes among undergraduate students prior vaccine distribution started. In a predominantly female $(79.8 \%)$ and Caucasian (85.9\%) sample of college students in South Carolina, perceived severity and fear of COVID-19 infection were positively associated with vaccine acceptance, while higher levels of risk exposures at work/study place and negative attitudes toward vaccinations in general were associated with low vaccine acceptance [18]. Another study at a large public university in the northwest United States found that students perceived a COVID-19 vaccination as more important than influenza vaccination [19]. However, at the time of this study, no research had examined vaccine acceptance among more diverse college student populations. Furthermore, to our knowledge, no study has examined the number of college students already vaccinated, or factors associated with being already vaccinated.

The college years represent a critical time for developing positive health behaviors and health decision-making practices [20]. Possessing adequate knowledge and utilization of reliable information sources may play an important role in adoption of positive health behaviors, including acceptance of vaccinations [21, 22]. Prior studies have shown that the most common vaccine-related information sources for college students are the internet [23], personal networks and social media [24]. Of concern is that the spread of misinformation on the internet has led to distrust of vaccines [9]. Furthermore, the degree of trust in the source of information could also shape college students' attitudes regarding COVID-19 vaccines. Among a sample of college students in South Carolina, higher acceptance of COVID-19 vaccine was significantly associated with increased trust levels in mass media, health agencies, scientists, and pharmaceutical companies [24].

This investigation had two primary aims: (1) to examine whether some college students have already been vaccinated, including factors (e.g., vaccine knowledge, attitudes, and history) associated with being already vaccinated; and (2) given previously documented hesitancy regarding COVID19 vaccines in the US population, to determine college students' intention for COVID-19 vaccination and factors associated with intention to get vaccinated (i.e., vaccine knowledge, attitudes, and history), among those who have not been vaccinated yet. Identifying factors associated with vaccine uptake and intention to receive a vaccine can assist with development of strategies aimed at improving COVID19 vaccine acceptability and uptake among college students.

\section{Methods}

A simple random sample of 2341 students (both undergraduate and graduate), obtained through the Institutional Effectiveness Office, at a diverse, public university in Northern New Jersey were invited to participate in this study. An anonymous cross-sectional online survey of students was administered using the Qualtrics platform (Qualtrics, Provo, UT) during three weeks in February and March 2021. Students received an anonymous link to the survey through their email, with two reminders following in the ensuing weeks. Informed consent was provided by all participants prior to completing the online survey. All data were self-reported. A total of 457 students completed the self-administered survey (response rate $=19.5 \%$ ). Students were given an opportunity to enter a raffle to win one of ten $\$ 20$ gift cards. The University Institutional Review Board (IRB) approved the study.

To assess whether participants have already been vaccinated, a single yes/no question "Have you already received a COVID-19 vaccine?" was asked. Intention to get vaccinated was determined on a 5-point scale ranging from $1=$ "strongly disagree" to $5=$ "strongly agree" with the following statement: "I would be willing to receive a vaccine against COVID-19 if made available to college students". Values were dichotomized to 0 (strongly disagree, disagree, neutral) and 1 (agree, strongly agree). Collected demographic information included age (recorded as continuous variable), sex (male, female, other), ethnicity (Hispanic/non-Hispanic), race, class level (freshman, sophomore, junior, senior, graduate student), major, and current employment (yes/no), followed by question on the type/industry of employment.

Students were asked a total of 6 "Yes/No" questions in regard to their COVID-19 testing history, their or family members' COVID-19 diagnosis, and whether their family members have already received vaccine, including whether family members reported of any negative reaction/side effect to vaccine. A total of 7 knowledge questions were asked (e.g., "Vaccines produce an immune response similar to that produced by the natural infection, but they do not subject the recipient to the disease and its potential complications"). Responses were recorded as "true/false/unsure". A 
composite variable was created indicating correct answers to all seven questions.

Students were asked which information sources (i.e. government, doctors, news sites, friends) they trust to provide accurate COVID-19 vaccine information and could select all that applied. Additionally, students were asked how often they use these sources to get information about vaccines, how often they find this information confusing and hard to understand, and how often they check the credibility of the source. All questions were assessed on a 5-point scale that ranges from $0=$ "never" to $4=$ "always". Values were dichotomized to 0 (never, rarely, sometimes) and 1 (often, always).

A total of 14 questions assessed participants' attitudes regarding COVID-19 vaccine. All questions were assessed using a 5-point Likert scale $(0=$ "strongly disagree" to $4=$ "strongly agree"). Among others, questions assessed participants' trust ("COVID-19 vaccines currently available are safe and effective"), belief in vaccine efficacy ("Vaccination decreases my chance of getting COVID-19 or its complications"), concerns about side effects ("I am concerned about possible side effects of COVID-19 vaccines"), or attitude regarding resuming in-person classes upon vaccination ("I would feel more confident in attending in-person classes if the COVID-19 vaccine is required for all students"). The statements were formed based on previous literature on vaccine attitude and hesitancy [16, 24, 25]. Values were dichotomized to 0 (strongly disagree/disagree/neutral) and 1 (agree/ strongly agree). A sum score was generated with a higher score indicating more positive attitude toward COVID-19 vaccination. The Cronbach's alpha for the fourteen items was 0.84 . Students were asked 4 questions on their more recent vaccination history (i.e., "Have you been vaccinated against flu this season?", and "Have you been vaccinated against other infectious diseases, e.g., HPV?"). Responses were recorded as "Yes/No/Do not remember".

Statistical analyses were conducted using the Statistical Package for Social Sciences, SPSS, 27.0 (IBM). Descriptive analyses examined the distribution (e.g., frequencies, means) of all variables of interest. Next, separate binary logistic regressions were computed examining how various independent variables (i.e., demographics, COVID-19 history, vaccine history, vaccine knowledge, sources of information, and attitude) relate to each of two main outcomes, i.e., being vaccinated and intention to receive vaccine. Next, we entered all bivariate correlates that achieved significance of less than 0.05 into multivariable logistic regression models to evaluate the association of independent variables with two main outcomes, while controlling for the potentially confounding effects of other variables in models. To prevent over-fitting the logistic regression model, collinearity between predictor variables was assessed using a correlation matrix procedure. Variables were considered collinear if the value of the correlation coefficient was greater than
0.6 [26]. None of variables showed this level of collinearity. Hosmer and Lemeshow tests confirmed that the predictors were a good fit for each model. The explanatory power of the models estimating two main outcomes was estimated with Nagelkerke's $\mathrm{R}^{2}$. Odds ratios (ORs), $95 \%$ confidence intervals (CIs), and $p$-values are reported, together with the test-statistic for the main model.

\section{Results}

Table 1 shows the demographic characteristics of our sample. The median age of our sample was 22 years (range 18-47). The sample was majority female $(74.8 \%)$, and equally split between non-Hispanic Whites and racial/ethnic minorities. One quarter of the participants were freshmen or sophomores, while a quarter were graduate students. Slightly more than one third were in health majors (e.g., nursing, public health), while $70 \%$ were employed either full or part-time, of which $20 \%$ were health care workers or first responders.

Table 2 presents descriptive statistics for observed indicators of COVID-19 history, COVID-19 vaccine knowledge, sources and utilization of information related COVID-19

Table 1 Socio-demographic characteristics of the study participants $(\mathrm{N}=457)$

\begin{tabular}{lll}
\hline Variable & Category & $\mathrm{N}(\%)$ \\
\hline Age & Mean \pm SD & $24.7 \pm 6.38$ \\
& Median, IQR & $22(20,28)$ \\
& Range & $18-47$ \\
Sex & Female & $342(74.8)$ \\
& Male & $109(23.9)$ \\
Race/ethnicity & Other/prefer not to say & $6(1.3)$ \\
& Non-Hispanic White & $226(49.5)$ \\
& Non-White & $231(50.5)$ \\
& African American/Black & $52(11.4)$ \\
Class level & Asian American & $34(7.4)$ \\
& Others (incl. Hispanic) & $145(31.7)$ \\
& Freshman & $51(11.2)$ \\
First responder (EMT, firefighter) & $64(14.0)$ \\
& Sophomore & $102(22.3)$ \\
& Junior & $120(26.3)$ \\
Major & Senior & $120(26.3)$ \\
Employed & Graduate student & $159(34.8)$ \\
& Health or sciences & $298(65.2)$ \\
& Non-health/science & $141(30.9)$ \\
& Yes, full-time & $177(38.7)$ \\
& Yes, part-time & $139(30.4)$ \\
& No & $10(2.2)$ \\
\hline
\end{tabular}


Table 2 Descriptive statistics for observed indicators of COVID-19 history, vaccine knowledge, utilization of information related to COVID-19, sources of information, and vaccination history

\begin{tabular}{|c|c|c|}
\hline Variable & Category & $\mathrm{N}(\%)$ \\
\hline \multicolumn{3}{|l|}{ I Main outcomes } \\
\hline \multicolumn{2}{|l|}{ Already received COVID-19 vaccine, $\mathrm{N}=457$} & $105(23.0)$ \\
\hline \multicolumn{2}{|c|}{ Willing to receive vaccine if made available to college students, unvaccinated only, $\mathrm{N}=352$} & $186(52.8)$ \\
\hline \multicolumn{3}{|l|}{ II COVID-19 history } \\
\hline \multicolumn{2}{|l|}{ Ever tested for COVID-19 } & $332(72.6)$ \\
\hline \multicolumn{2}{|l|}{ Diagnosed with COVID-19 } & $62(13.6)$ \\
\hline \multicolumn{2}{|l|}{ Family member diagnosed with COVID-19 } & $157(34.4)$ \\
\hline \multicolumn{2}{|l|}{ Lost family member to COVID-19 } & $62(13.6)$ \\
\hline \multicolumn{2}{|l|}{ Family member or friend received COVID-19 vaccine } & $329(72.0)$ \\
\hline \multicolumn{2}{|l|}{ Family member/friend reported side effect of vaccine $(\mathrm{N}=329)$} & $139(30.4)$ \\
\hline \multicolumn{3}{|l|}{ III Vaccine knowledge } \\
\hline \multirow{8}{*}{$\begin{array}{l}\text { Vaccine knowledge questions } \\
\text { correctly answered } \\
\text { (true/false/don't know) }\end{array}$} & Correct answers provided to ALL statements & $95(20.8)$ \\
\hline & $\begin{array}{l}\text { 1. Scientific evidence supports associations between vaccines } \\
\text { and diseases such as autism and multiple sclerosis (correct } \\
\text { answer =F) }\end{array}$ & $255(55.8)$ \\
\hline & 2. Vaccinations increase the occurrence of allergies $(F)$ & $208(45.5)$ \\
\hline & $\begin{array}{l}\text { 3. Vaccines produce an immune response similar to that } \\
\text { produced by the natural infection, but they do not subject the } \\
\text { recipient to the disease and its potential complications }(\mathrm{T})\end{array}$ & $312(68.3)$ \\
\hline & 4. COVID-19 vaccines can change my genes $(\mathrm{F})$ & $309(67.6)$ \\
\hline & 5. COVID-19 vaccines can cause infertility $(\mathrm{F})$ & $221(48.4)$ \\
\hline & $\begin{array}{l}\text { 6. The currently available COVID-19 vaccines have been tested } \\
\text { only on a small number (i.e., hundred) of people. (F) }\end{array}$ & $247(54.0)$ \\
\hline & $\begin{array}{l}\text { 7. The currently available COVID-19 vaccines have been given } \\
\text { to thousands of people and checked for efficacy and safety (T) }\end{array}$ & $298(65.2)$ \\
\hline \multicolumn{3}{|l|}{ IV Vaccine information } \\
\hline \multirow{4}{*}{$\begin{array}{l}\text { Consumption of information related to COVID-19 vaccines } \\
\text { (Often/Very often) }\end{array}$} & 1. Read or listen COVID-19 vaccine information & $163(35.6)$ \\
\hline & $\begin{array}{l}\text { 2. Find COVID-19 vaccine information confusing and/or hard to } \\
\text { understand }\end{array}$ & $207(45.3)$ \\
\hline & 3. Discuss COVID-19 vaccine information with other people & $224(49.0)$ \\
\hline & 4. Check credibility of COVID-19 vaccine information & $208(45.5)$ \\
\hline \multirow[t]{9}{*}{ Trust in sources of information regarding COVID-19 vaccines } & Official sources & $392(85.8)$ \\
\hline & Government & $357(78.1)$ \\
\hline & County Health Department & $234(51.2)$ \\
\hline & Health professionals & $289(63.2)$ \\
\hline & University & $112(24.5)$ \\
\hline & Unofficial sources & $95(20.8)$ \\
\hline & Social media & $32(7.0)$ \\
\hline & Friends and family & 75 (16.4) \\
\hline & News sources & $95(20.8)$ \\
\hline
\end{tabular}

vaccines, COVID-19 vaccine attitudes, and vaccination history. In the current sample, 105 (23\%) participants reported being already vaccinated, while among non-vaccinated students $(\mathrm{N}=352), 52.8 \%$ indicated intention to vaccinate when the vaccine is made available to college students. Nearly three-quarters $(72.6 \%)$ of participants reported ever being tested for COVID-19, while $13.6 \%$ reported being diagnosed with COVID-19. One-third (34.4\%) reported family member(s) being diagnosed with COVID-19, and $13.6 \%$ reported losing a family member due to COVID-19. Almost three-quarters (72\%) of participants reported a family member receiving COVID-19 vaccine.

While individual knowledge statements were correctly answered by between $45.5 \%$ and $68.3 \%$ of participants depending on the question, only $20.8 \%$ of students provided correct answers to all knowledge questions. Interestingly, only about one-third of respondents indicated that they read and listen to information about COVID-19, yet about half 
Table 2 (continued)

\begin{tabular}{|c|c|c|}
\hline Variable & Category & $\mathrm{N}(\%)$ \\
\hline \multicolumn{3}{|l|}{$V$ Vaccine attitudes } \\
\hline \multirow[t]{18}{*}{ Level of agreement (agree/strongly agree) } & $\begin{array}{l}\text { Composite score of positive attitudes in regard to COVID-19 } \\
\text { vaccine }(0-13)\end{array}$ & \\
\hline & Mean \pm SD & $7.67 \pm 3.42$ \\
\hline & Median, IQR & $8(4,11)$ \\
\hline & Range & $2-13$ \\
\hline & Individual statements & \\
\hline & $\begin{array}{l}\text { 1. I would be less worry about COVID-19 after getting vac- } \\
\text { cinated }\end{array}$ & $242(53.0)$ \\
\hline & $\begin{array}{l}\text { 2. I feel responsible to receive the vaccine to protect other people } \\
\text { from COVID-19 }\end{array}$ & $276(60.4)$ \\
\hline & $\begin{array}{l}\text { 3. Until I receive a COVID-19 vaccine, there is very little I can } \\
\text { do to prevent getting infected with COVID-19 }\end{array}$ & $57(12.5)$ \\
\hline & 4. There is no need to vaccinate because natural immunity exists & $36(7.9)$ \\
\hline & 5. Young adults do not need to be vaccinated for COVID-19 & $6(5.7)$ \\
\hline & 6. COVID-19 vaccines currently available are safe and effective & $216(47.3)$ \\
\hline & $\begin{array}{l}\text { 7. I am concerned about possible side effects of COVID-19 } \\
\text { vaccines }\end{array}$ & $209(45.7)$ \\
\hline & $\begin{array}{l}\text { 8. I would receive the COVID- } 19 \text { vaccine only if I were given } \\
\text { adequate information about it }\end{array}$ & $210(46.0)$ \\
\hline & 9. Whether or not I get the vaccine should be entirely up to me & $270(59.1)$ \\
\hline & $\begin{array}{l}\text { 10. I would feel more confident in attending in-person classes if } \\
\text { the COVID-19 vaccine is required for all students }\end{array}$ & $226(49.5)$ \\
\hline & $\begin{array}{l}\text { 11. I would feel more confident socializing with other people if } \\
\text { they have been vaccinated for COVID- } 19\end{array}$ & $263(57.5)$ \\
\hline & $\begin{array}{l}\text { 12. My family and friends would want me to receive the } \\
\text { COVID-19 vaccine }\end{array}$ & $244(53.4)$ \\
\hline & $\begin{array}{l}\text { 13. Vaccination decreases my chance of getting COVID-19 or its } \\
\text { complications }\end{array}$ & $278(60.8)$ \\
\hline
\end{tabular}

VI Vaccine history $(N=400)$

of participants reported discussing COVID-19 vaccines with family and friends. Many students (45.3\%) find information about COVID-19 vaccines difficult to understand. The most trusted sources of information regarding COVID-19 vaccines were official sources: government (78.1\%), followed by medical professionals $(63.2 \%)$, while only $7 \%$ said they trusted social media as a source of information.

The statements "It is my responsibility to receive the vaccine to protect other people from COVID-19" and "Vaccination decreases my chance of getting COVID-19 or its complications", received the highest endorsement, with $60.4 \%$ and $60.8 \%$ either agreeing or strongly agreeing, respectively. Additionally, over half of participants indicated that they would feel less worry about COVID-19 once vaccinated $(53.0 \%)$, that their family and friends would want them to vaccinate $(53.4 \%)$, and that they would feel more confident to socialize with other people who have been vaccinated $(57.5 \%)$. Only $5.7 \%$ of students either agreed or strongly agreed that young adults do not need to be vaccinated for COVID-19, while only $7.9 \%$ either agreed or strongly agreed that there is no need to vaccinate because natural immunity exists. However, a significant proportion of participants (59.1\%) indicated that it should be up to them to decide whether they would get vaccine. When asked about vaccination history, $52.8 \%$ of students stated that they have been vaccinated against other infectious diseases (i.e., human papilloma virus, HPV), while $44.6 \%$ reported being vaccinated against flu this season.

Factors related to participants' already receiving vaccine against COVID-19 are presented in Table 3 in the form of unadjusted and adjusted OR. Unadjusted OR indicate that students who are older, junior/senior/or graduate, health major, employed, and health care worker had higher odds of being vaccinated. Those who had a family member already vaccinated, correctly answered all of knowledge questions, frequently read, discussed, and checked the credibility of 
Table 3 Unadjusted and adjusted binary logistic regression models examining the factors associated with being already vaccinated $(\mathrm{N}=457)$

\begin{tabular}{|c|c|c|}
\hline Variables & Unadjusted OR (95\% CI) & $\begin{array}{l}\text { Adjusted OR }(95 \% \mathrm{CI}) \\
\mathrm{R}^{2}=0.37\end{array}$ \\
\hline \multicolumn{3}{|l|}{ Demographics } \\
\hline Age & $1.06(1.03-1.10)^{* * *}$ & $1.04(0.99-1.08) n s$ \\
\hline Gender (female) & $1.36(0.80-2.29) n s$ & - \\
\hline Race (non-White) & $0.82(0.53-1.27) n s$ & - \\
\hline Upper class level (junior/senior/graduate) & $2.89(1.55-5.39)^{* * *}$ & $1.60(0.73-3.49) n s$ \\
\hline Health major & $1.74(1.11-2.71)^{*}$ & $0.86(0.46-1.69) n s$ \\
\hline Employment & $3.58(1.96-6.55)^{* * *}$ & $1.86(0.92-3.79) n s$ \\
\hline Health care worker/first responder & $5.82(3.55-9.60)^{* * *}$ & $4.17(2.11-8.23)^{* * *}$ \\
\hline \multicolumn{3}{|l|}{ COVID-19 history } \\
\hline Family member diagnosed with COVID-19 & $1.05(0.67-1.67) n s$ & - \\
\hline Lost family member to COVID-19 & $0.97(0.51-1.84) n s$ & - \\
\hline Family member or friend received COVID-19 vaccine & $8.75(3.73-20.53) * * *$ & $5.03(2.00-2.60)^{* * *}$ \\
\hline \multicolumn{3}{|l|}{ Vaccine knowledge, information consumption, and trust } \\
\hline Correct answers to all knowledge statements & $2.76(1.69-4.50)^{* * *}$ & $1.22(0.65-2.30) n s$ \\
\hline Frequently reads information on vaccine & $2.13(1.37-3.32)^{* * *}$ & $0.87(0.45-1.67) n s$ \\
\hline Finds vaccine information confusing & $0.76(0.49-1.18) n s$ & - \\
\hline Discusses vaccine information with others & $3.22(2.01-5.14)^{* * *}$ & $1.83(0.97-3.44) n s$ \\
\hline Checks credibility of vaccine information & $2.50(1.60-3.92)^{* * *}$ & $1.14(0.60-2.17) n s$ \\
\hline Trust official (govern., medical professionals) sources & $2.34(1.08-5.08)^{*}$ & $1.64(0.31-8.68) n s$ \\
\hline Trust news media & $1.09(0.64-1.85) n s$ & - \\
\hline Trust unofficial (social media, friends/family) sources & $1.17(0.69-1.98) n s$ & - \\
\hline \multicolumn{3}{|l|}{ Attitudes regarding COVID-19 vaccine } \\
\hline Composite score for Positive Attitude regarding COVID-19 vaccine & $1.19(1.11-1.28)^{* * *}$ & $1.16(1.04-1.29)^{* * *}$ \\
\hline \multicolumn{3}{|l|}{ Vaccine history } \\
\hline Vaccinated against flu this season & $3.85(2.41-6.15)^{* * *}$ & $1.97(1.11-3.51)^{*}$ \\
\hline Vaccinated against other infectious diseases (i.e., HPV) & $1.22(0.78-1.88) n s$ & - \\
\hline
\end{tabular}

OR odds ratio, $n s$ non-significant

$* \mathrm{p}<0.05 ; * * \mathrm{p}<0.01 ; * * * \mathrm{p}<0.001$

information about vaccines, and indicated trust in official sources of information regarding COVID-19 vaccines also had higher odds of being vaccinated. Those with a higher composite score for more positive attitude were at higher odds of being vaccinated. Finally, those who were vaccinated against flu this season were also more likely to receive COVID-19 vaccine. In the multivariable model, relative to those who were not vaccinated, participants who were health care workers $(\mathrm{aOR}=4.17,95 \%$ CI $2.11-8.23, \mathrm{p}<0.001)$, had a family member who received COVID-19 vaccine $(\mathrm{aOR}=5.03,95 \% \mathrm{CI} 2.00-62.60, \mathrm{p}<0.001)$, exhibited more overall positive attitude regarding vaccination $(\mathrm{aOR}=1.12$, 95\% CI 1.04-1.29, $\mathrm{p}<0.001$ ), and received seasonal flu vaccine $(\mathrm{aOR}=1.97,95 \%$ CI $1.11-3.51, \mathrm{p}<0.05)$ were more likely to have received the COVID-19 vaccine.

In Table 4 we present descriptive statistics for observed indicators among non-vaccinated participants, and both unadjusted and adjusted OR for associations between participants' intention to receive vaccine against COVID-19 and observed indicators. In the bivariate analysis, being older and White was associate with higher odds of intending to vaccinate. Those who had a vaccinated family member, correctly answered all knowledge questions, frequently read, discussed, and checked the credibility of information about vaccines, and indicated trust in official sources of information or news media regarding COVID-19 vaccines were also with higher odds to endorse intention to get vaccinated. Those who intend to get vaccinated had higher odds of scoring higher on attitude scale. Finally, those who previously received vaccines against flu and other infectious diseases (e.g., HPV) were more likely to indicate they will receive COVID-19 vaccine when it becomes available to college students. In the multivariable model, adjusted for all other significant variables from bivariate analysis, relative to those who did not indicate intention to vaccinate, participants who discuss COVID-19 vaccine information with others $(\mathrm{aOR}=5.38,95 \%$ CI $1.11-13.17, \mathrm{p}<0.001)$ and exhibited more overall positive attitude regarding vaccination 
Table 4 Unadjusted and adjusted binary logistic regression models examining the factors associated with intention to get vaccinated among nonvaccinated $(\mathrm{N}=352)$

Variables
Descriptive statistics of Unadjusted OR (95\% CI) Adjusted OR (95\% CI) unvaccinated students

$\mathrm{N}(\%)$

$$
\mathrm{R}^{2}=0.76
$$

\section{Demographics}

Age $($ mean \pm SD)

Gender (female)

$24.1( \pm 6.1)$

Race (non-White)

$259(73.6)$

Upper class level (junior/senior/graduate)

$182(51.7)$

Health major

$250(71.0)$

Employment

$112(31.8)$

$227(64.5)$

Health care worker/first responder

$43(12.2)$

COVID-19 history

Family member diagnosed with COVID-19

$120(34.1)$

Lost family member to COVID-19

48 (13.6)

Family member or friend received COVID-19 vaccine

$230(65.3)$

Vaccine knowledge, information consumption, and trust

Correct answers to all knowledge statements

Frequently reads/listens information on vaccine

$58(16.5)$

Finds vaccine information confusing

$111(31.5)$

$165(46.9)$

Discusses vaccine information with others

$150(42.6)$

$142(40.3)$

Checks credibility of vaccine information

$295(83.8)$

Trust official (govern., medical professionals) sources

$71(20.2)$

Trust unofficial (social media, friends/family) sources

$72(20.5)$

Trust news media

$7.24( \pm 3.42)$

Composite score for Positive Attitude regarding COVID-19 vaccine $7.24( \pm 3.42)$

Vaccine history

Vaccinated against flu this season

$131(37.2)$

Vaccinated against other infectious diseases (i.e., HPV)

$\begin{array}{ll}0.97(0.93-1.00)^{*} & 0.95(0.89-1.012) n s \\ 0.80(0.49-1.28) n s & - \\ 0.45(0.29-0.69)^{* * *} & 1.14(0.52-2.48) n s \\ 1.17(0.74-1.86) n s & - \\ 1.51(0.96-2.39) n s & - \\ 0.86(0.56-1.34) n s & - \\ 0.54(0.28-1.04) n s & - \\ & \\ 0.84(0.54-1.31) n s & - \\ 1.29(0.70-2.40) n s & - \\ 2.44(1.55-3.82)^{* * *} & 1.06(0.45-2.46) n s\end{array}$

$7.26(3.33-15.85) * * *$

$0.81(0.23-2.77) n s$

$1.04(0.68-1.58) n s$

$3.31(2.12-5.17)^{* * *}$

$0.94(0.36-2.45) n s$

-

$5.38(2.11-13.7) * * *$

$2.39(1.54 .3 .71)^{* * *}$

$0.52(0.21-1.26)$

$0.90(0.24-3.38) n s$

$11.02(4.83-25.15)^{* * *}$

$1.38(0.81-2.34) n s$

$-$

$2.22(1.29-3.85)^{* *}$

$0.49(0.18-1.29) n s$

$2.36(2.00-2.77) * * *$

$2.69(2.12-3.43)^{* * *}$

$2.86(1.81-4.51)^{* * *}$

$0.68(0.30-1.54) n s$

$2.84(1.84-437) * * *$
$3.50(2.14-5.71) * * *$

$* \mathrm{p}<0.05 ; * * \mathrm{p}<0.01 ; * * * \mathrm{p}<0.001$

$(\mathrm{aOR}=2.69,95 \%$ CI 2.12-3.43, $\mathrm{p}<0.001)$ were more likely to indicate intention to receive the COVID-19 vaccine.

\section{Discussion}

Unprecedented efforts are unfolding in the U.S. to quickly vaccinate as many individuals as possible and change the course of the COVID-19 pandemic. Yet, the virus continues to upend normal life, including in U.S. higher education institutions. While colleges and universities have implemented multiple measures to curb the spread of the virus, major outbreaks on U.S. college campuses continue [27]. As vaccines become more widely available, a few studies have emerged describing college students' intentions and attitudes regarding vaccine uptake $[16,19,24]$. The current study adds to this growing body of literature by examining the number of students that have already received the vaccine, as well as vaccine intentions among those who have not received it yet.

This study is among the first that examines the current COVID-19 vaccination coverage among a diverse sample of college students in the US. Our findings indicate that $23 \%$ of students from our sample have already received the COVID19 vaccine. Not surprisingly, students employed as health care workers or first responders were more likely to get vaccinated. This is consistent with AIPAC recommendations for phase $1 \mathrm{~A}$ and $1 \mathrm{~B}$ of vaccine distribution in the U.S. [28], which aimed to achieve high COVID-19 vaccination coverage rates in this group as soon as a vaccine was available. Additionally, students with a vaccinated family member were more likely to be vaccinated themselves. Consistent with findings that over half of respondents indicated that family and friends would want them to receive a COVID-19 vaccine, family encouragement seems to play an important 
role in vaccine acceptance. This is in agreement with previous findings on the importance of parental influences on HPV vaccination among adolescents and young adults [29]. We also found that more positive overall attitudes toward COVID-19 vaccination were independently associated with higher uptake of vaccine. While many college students feel responsible to receive the vaccine to protect others from infection or to decrease chances of experiencing severe illness, positive social outcomes such as an end to social isolation or attending in-person classes may be an important driver for increased uptake of vaccine in this population. It is also encouraging that only a small number of students (5.7\%) indicated that young adults should not be vaccinated against COVID-19. Finally, data from the current study indicates that receiving a vaccine against influenza is an indicator of being vaccinated against COVID-19. Students who are health care workers may have an opportunity to receive both. It is important to note that acceptance of influenza vaccine is traditionally low among young adults in the U.S. [30], which was confirmed by this study with less than half of participants receiving flu vaccine this year. Yet, research has shown that college students perceive COVID-19 vaccination as significantly more important than influenza vaccination [19].

Among non-vaccinated students, just over half (52.8\%) expressed intention to receive the vaccine. Although this number is lower than a previously published study on COVID-19 vaccine intentions among college students in the northwestern U.S. [19], it is similar to data among nursing students [16], and the general US adult population [31]. Reported levels of intent to receive the COVID-19 vaccine seem inadequate and may necessitate additional efforts by college administrators to increase vaccine acceptability among students. Although non-White students were significantly less likely to express intent to vaccinate in bivariate analysis, after controlling for other co-variates, we found no difference in intent to receive vaccine between non-White and White participants. One of the strongest correlates of intention to vaccinate was whether participants discussed vaccine information with others. While this finding deserves further investigation, previous research has shown that discussion with a provider is one of the key determinants of vaccination behaviors [32]. Strong recommendations from health educators and health care providers may be critical to promote vaccine uptake among college students. More positive attitudes towards vaccination was a strong predictor of intention to vaccinate which is similar to other studies $[17,19]$.

Although intentions are linked to behavior [33], it is important to note that vaccine intentions do not always follow uptake [34, 35]. Therefore, it will be important to monitor temporal changes in acceptability and uptake of vaccine. While school administrators may decide to mandate vaccination for all students in the fall [6], some have raised the issue whether schools have the right to require students to get vaccinated before returning to campus [36]. Furthermore, a significant number of students $(59.1 \%)$ indicated that individuals should have the right to choose whether to receive the vaccine. This may indicate that some students may be resistant to possible mandatory vaccinations. While a greater availability and access at no cost will increase likelihood of getting vaccinated, additional efforts to improve knowledge, attitudes, and beliefs among college students may be more prudent to increase the vaccine intention and uptake in this population.

\section{Limitations}

It is important to note that there are several limitations to this study. The cross-sectional design limits generalizability and the ability to establish causality. Given the limited resources available, the response rate is somewhat low (19.5\%), and we lack data on non-respondents. While the sample was selected in a random fashion, and demographic characteristics are reflective of student population at university, the data are self-reported and may be subject to social desirability bias. The content of our survey revolved around basic history, knowledge and attitudes regarding vaccines, and it is possible that respondents answered according to their personal beliefs, or vaccine endorsements by the authorities.

\section{Conclusions}

Our study findings fill an important gap in the literature and can serve as a foundation for larger, more generalizable studies that will inform planning and development of public health efforts to increase uptake of a COVID-19 vaccine among college students. The importance of increasing vaccination in this population cannot be understated as increased rates of vaccinated individuals on college campuses, coupled with other preventive behaviors will likely result in lower rates of community transmission and may ultimately play an important role in achieving herd immunity and safe return to normalcy on college campuses. Administrators may take such information into account when determining if COVID19 vaccination will be required of students, faculty and staff for a full return to camps in upcoming semesters. Partnering with local health officials and public health experts at the universities and local health departments, and organizing logistical support, i.e., scheduling system for students, may be important next step for administrators as they develop formal vaccinations plans. While students may be receiving information about vaccinations from various sources, better efforts are needed to lower vaccine hesitancy, increase 
informed decision making regarding COVID-19 vaccines and increase the vaccine uptake in this population.

Funding No funding was received for this study.

\section{Declarations}

Conflict of interest The authors declare that they have no conflict of interest.

\section{References}

1. Copeland, W. E., McGinnis, E., Bai, Y., Adams, Z., Nardone, H., Devadanam, V., Rettew, J., \& Hudziak, J. J. (2020). Impact of COVID on college student mental health and wellness. Journal of the American Academy of Child and Adolescent Psychiatry, S0890-8567(20), 31988-31992. https://doi.org/10.1016/j.jaac. 2020.08.466

2. Kecojevic, A., Basch, C. H., Sullivan, M., \& Davi, N. K. (2020). The impact of the COVID-19 epidemic on mental health of undergraduate students in New Jersey, cross-sectional study. PLoS ONE, 15(9), e0239696. https://doi.org/10.1371/journal.pone. 0239696

3. The New York Times. (2021, April 5). Those 16 or older in New Jersey will be eligible for a vaccine on April 19, the governor says. The New York Times. New York. Retrieved from https:// www.nytimes.com/2021/04/05/nyregion/new-jersey-covid-vacci ne-eligible.html

4. Fugleberg, J. (2021, March 10). South Dakota opens COVID19 vaccines to teachers, funeral workers, some college students. Jamestown Sun. Retrieved from https://www.jamestownsun.com/ newsmd/coronavirus/6927454-South-Dakota-opens-COVID-19vaccines-to-teachers-funeral-workers-some-college-students

5. American College Health Association. (2021). Mass vaccination clinic guidance and resources. Retrieved March 10, 2021, from https://www.acha.org/ACHA/Resources/COVID-19_ Novel_Coronavirus/Mass_Vaccination_Guidance_and_Resou rces/ACHA/Resources/Topics/Mass_Vaccination_Clinic_Guida nce_and_Resources.aspx?hkey=aa394485-cc39-417a-ab2e-bcddc 24f14ed

6. CNN. (2021). Rutgers University to require Covid-19 vaccine for students attending in the fall. Retrieved March 28, 2021, from https://www.cnn.com/2021/03/25/us/rutgers-covid-vaccine-stude nts/index.html

7. Schaffer Deroo, S., Pudalov, N. J., \& Fu, L. Y. (2020). Planning for a COVID-19 vaccination program. JAMA - Journal of the American Medical Association. https://doi.org/10.1001/jama.2020.8711

8. Pew Research Center. (2021). Growing share of Americans say they plan to get a COVID-19 vaccine-or already have. Retrieved March 10, 2021, from https://www.pewresearch.org/science/2021/ 03/05/growing-share-of-americans-say-they-plan-to-get-a-covid19-vaccine-or-already-have/

9. Dubé, E., Vivion, M., \& MacDonald, N. E. (2014). Vaccine hesitancy, vaccine refusal and the anti-vaccine movement: Influence, impact and implications. Expert Review of Vaccines. https://doi. org/10.1586/14760584.2015.964212

10. Barnard, M., George, P., Perryman, M. L., \& Wolff, L. A. (2017). Human papillomavirus (HPV) vaccine knowledge, attitudes, and uptake in college students: Implications from the Precaution
Adoption Process Model. PLoS ONE, 12(8), e0182266. https:// doi.org/10.1371/journal.pone.0182266

11. Wise, T., Zbozinek, T. D., Michelini, G., Hagan, C. C., \& Mobbs, D. (2020). Changes in risk perception and self-reported protective behaviour during the first week of the COVID-19 pandemic in the United States: COVID-19 risk perception and behavior. Royal Society Open Science. https://doi.org/10.1098/ rsos.200742rsos 200742

12. Jaiswal, J., \& Halkitis, P. N. (2019). Towards a more inclusive and dynamic understanding of medical mistrust informed by science. Behavioral Medicine. https://doi.org/10.1080/08964 289.2019.1619511

13. Bogart, L. M., Ojikutu, B. O., Tyagi, K., Klein, D. J., Mutchler, M. G., Dong, L., Lawrence, S. J., Thomas, D. R., \& Kellman, S. (2021). COVID-19 related medical mistrust, health impacts, and potential vaccine hesitancy among black Americans living with HIV. Journal of Acquired Immune Deficiency Syndromes, 86(2), 200-207. https://doi.org/10.1097/QAI.0000000000002570

14. Barello, S., Nania, T., Dellafiore, F., Graffigna, G., \& Caruso, R. (2020). 'Vaccine hesitancy' among university students in Italy during the COVID-19 pandemic. European Journal of Epidemiology, 35(8), 781-783. https://doi.org/10.1007/ s10654-020-00670-z

15. Pastorino, R., Villani, L., Mariani, M., Ricciardi, W., Graffigna, G., \& Boccia, S. (2021). Impact of COVID-19 pandemic on flu and COVID-19 vaccination intentions among university students. Vaccines, 9(2), 70. https://doi.org/10.3390/vaccines 9020070

16. Manning, M. L., Gerolamo, A. M., Marino, M. A., Hanson-Zalot, M. E., \& Pogorzelska-Maziarz, M. (2021). COVID-19 vaccination readiness among nurse faculty and student nurses. Nursing Outlook. https://doi.org/10.1016/j.outlook.2021.01.019

17. Lucia, V. C., Kelekar, A., \& Afonso, N. M. (2020). COVID-19 vaccine hesitancy among medical students. Journal of Public Health. https://doi.org/10.1093/pubmed/fdaa230

18. Qiao, S., Tam, C. C., \& Li, X. (2020). Risk exposures, risk perceptions, negative attitudes toward general vaccination, and COVID19 vaccine acceptance among college students in South Carolina. medRxiv. https://doi.org/10.1101/2020.11.26.20239483

19. Graupensperger, S., Abdallah, D. A., \& Lee, C. M. (2021). Social norms and vaccine uptake: College students' COVID vaccination intentions, attitudes, and estimated peer norms and comparisons with influenza vaccine. Vaccine. https://doi.org/10.1016/j.vacci ne.2021.03.018

20. Von Ah, D., Ebert, S., Ngamvitroj, A., Park, N., \& Kang, D. H. (2004). Predictors of health behaviours in college students. Journal of Advanced Nursing. https://doi.org/10.1111/j.1365-2648. 2004.03229. $\mathrm{x}$

21. Natipagon-Shah, B., Lee, E., \& Lee, S. Y. (2020). Knowledge, beliefs, and practices among U. S. college students concerning papillomavirus vaccination. Journal of Community Health. https:// doi.org/10.1007/s10900-020-00922-9

22. Shon, E. J., Choe, S., Lee, L., \& Ki, Y. (2021). Influenza vaccination among U.S. college or university students: A systematic review. American Journal of Health Promotion. https://doi.org/ 10.1177/0890117120985833

23. Landowska, K., Waller, J., Bedford, H., Rockliffe, L., \& Forster, A. S. (2017). Influences on university students' intention to receive recommended vaccines: A cross-sectional survey. British Medical Journal Open. https://doi.org/10.1136/bmjopen-2017-016544

24. Qiao, S., Friedman, D. B., Tam, C. C., Zeng, C., \& Li, X. (2020). Vaccine acceptance among college students in South Carolina: Do information sources and trust in information make a difference? medRxiv. https://doi.org/10.1101/2020.12.02.20242982

25. Fisher, K. A., Bloomstone, S. J., Walder, J., Crawford, S., Fouayzi, H., \& Mazor, K. M. (2020). Attitudes toward a potential 
SARS-CoV-2 vaccine: A survey of U.S. adults. Annals of Internal Medicine, 173(12), 964-973. https://doi.org/10.7326/M20-3569

26. Tabachnick, B. G., \& Fidell, L. S. (2013). Using multivariate statistics 5. Boston: Pearson Allyn and Bacon (6th ed.). Pearson. Retrieved from https://www.pearson.com/us/higher-education/ program/Tabachnick-Using-Multivariate-Statistics-6th-Edition/ PGM332849.html

27. The New York Times. (2020). Tracking the coronavirus at U.S. colleges and universities. Retrieved March 10, 2021, from https:// www.nytimes.com/interactive/2020/us/covid-college-cases-track er.html

28. Dooling, K., McClung, N., Chamberland, M., Marin, M., Wallace, M., Bell, B. P., Lee, G. M., Talbot, H. K., Romero, J. R., \& Oliver, S. E. (2020). The Advisory Committee on Immunization Practices' Interim Recommendation for allocating initial supplies of COVID-19 Vaccine-United States, 2020. MMWR. Morbidity and Mortality Weekly Report, 69(49), 1857-1859. https://doi.org/ 10.15585/mmwr.mm6949e1

29. Wilson, K. L., White, A., Rosen, B. L., Chiappone, A., Pulczinski, J. C., Ory, M. G., \& Smith, M. L. (2016). Factors associated with college students' intentions to vaccinate their daughters against HPV: Protecting the next generation. Journal of Community Health, 41(5), 1078-1089. https://doi.org/10.1007/ s10900-016-0192-8

30. Centers for Disease Control and Prevention, C. (2020). Flu vaccination coverage, United States, 2019-20 Influenza Season I FluVaxView I Seasonal Influenza (Flu). Retrieved March 30, 2021, from https://www.cdc.gov/flu/fluvaxview/coverage-1920estima tes.htm

31. Daly, M., \& Robinson, E. (2020). Willingness to vaccinate against COVID-19 in the US: Longitudinal evidence from a nationally representative sample of adults from April-October 2020. medRxiv. https://doi.org/10.1101/2020.11.27.20239970
32. Rodriguez, S. A., Mullen, P. D., Lopez, D. M., Savas, L. S., \& Fernández, M. E. (2020, February 1). Factors associated with adolescent HPV vaccination in the U.S.: A systematic review of reviews and multilevel framework to inform intervention development. Preventive Medicine. https://doi.org/10.1016/j.ypmed.2019. 105968

33. Ajzen, I. (1991). The theory of planned behavior. Organizational Behavior and Human Decision Processes, 50(2), 179-211. https:// doi.org/10.1016/0749-5978(91)90020-T

34. Maurer, J. (2016). Inspecting the mechanism: A longitudinal analysis of socioeconomic status differences in perceived influenza risks, vaccination intentions, and vaccination behaviors during the 2009-2010 influenza pandemic. Medical Decision Making, 36(7), 887-899. https://doi.org/10.1177/0272989X15608379

35. Ye, L., Fang, T., Cui, J., Zhu, G., Ma, R., Sun, Y., Li, P., Li, H., Dong, H., \& Xu, G. (2021). The intentions to get vaccinated against influenza and actual vaccine uptake among diabetic patients in Ningbo, China: Identifying motivators and barriers. Human Vaccines and Immunotherapeutics, 17(1), 106-118. https://doi.org/10.1080/21645515.2020.1761201

36. Reiss, D. (2021). Can employers mandate a vaccine under emergency use authorization? Bill of Health. Retrieved March 28, 2021, from https://blog.petrieflom.law.harvard.edu/2021/02/24/ employer-mandate-covid-vaccine-eua/

Publisher's Note Springer Nature remains neutral with regard to jurisdictional claims in published maps and institutional affiliations. 